\title{
Eco(Teo)logia: discurso teológico ambiental x prática comunitária evangélica
}

\section{Eco(Theo)logy: Environmental Theological Discourse $\mathrm{x}$ Evangelical Community Practice}

\author{
Amelia Ferreira Martins LIMEIRA* \\ Maristela Oliveira de ANDRADE**
}

\begin{abstract}
RESUMO
O objetivo deste artigo é discutir as problemáticas que se inscrevem na intersecção entre sociedade e natureza, apresentando a Eco(Teo)logia como uma proposta interdisciplinar que procura convergir os discursos científico e religioso integrando a Ecologia e a Teologia em sua reflexão sobre o meio ambiente. Para a Eco(Teo)logia, é imprescindível a contribuição da tradição discursiva bíblica, por meio de releituras das narrativas da criação, da destruição e da restauração, encontradas nos livros de Gênesis e Apocalipse das Escrituras Sagradas judaico-cristãs. Para uma análise sobre esta formação discursiva, foi feita uma incursão nas contribuições de alguns teólogos, como Cullmann (1996), Murad (2009), Pfeiffer (1999), Reimer (2006, 2011), Stott $(2010,2011)$ e Wolff (2007), cuja abordagem está focada na proposta de torná-la um instrumento para a conscientização ambiental, contribuindo para o engajamento das causas ecológicas por parte da Igreja Evangélica. Mas, como esse discurso encontra-se ainda muito restrito a certas esferas institucionais, não alcançando contingentes mais amplos de evangélicos, este trabalho procura questionar e compreender como os textos bíblicos podem inspirar uma visão eco(teo)lógica, visando verificar se o discurso teológico pode, de fato, contribuir para uma conscientização ambiental, apresentando as práticas institucional e eclesiástica do discurso teológico ambiental evangélico. A pesquisa investigou a participação de algumas ONGs Cristãs Evangélicas, a Convenção Batista Brasileira, a Igreja Batista no Brasil na cidade de Cabedelo, PB, para melhorar a qualidade de vida das comunidades locais por meio do estímulo a ações de responsabilidade dos fiéis evangélicos.
\end{abstract}

Palavras-chave: Eco(Teo)logia; discurso; Igreja Batista.

\begin{abstract}
The purpose of this article is to discuss the issues that are at the intersection between society and nature presenting Eco(Theo)logy as an interdisciplinary approach that seeks to converge the scientific and reli-
\end{abstract}

\footnotetext{
" Mestra em Desenvolvimento e Meio Ambiente (UFPB). Servidora técnico-administrativa em Educação da Universidade Federal da Paraíba (UFPB). E-mail: missionaria_amelia@hotmail.com

** Doutorado em Doctorat de Troisieme Cycle (Universite de Paris III, France). Professora da Universidade Federal da Paraíba (UFPB). E-mail: andrademaristela@hotmail.com
} 
gious discourses integrating Ecology and Theology in its reflection on the environment. For Eco(Theo) logy the contribution of biblical discursive tradition whose corpus consists of the narratives of creation, destruction and restoration found in the books of Genesis and Revelation of the Judeo-Christian Scriptures is essential. For an analysis of this discursive formation, it was made a foray into the contributions of some theologians as Cullmann (1996), Murad (2009), Pfeiffer (1999), Reimer (2006, 2011), Stott $(2010,2011)$ and Wolff (2007), whose approach is focused in the proposal that becomes an instrument for environmental awareness and thus contribute to the formation of a new ecological awareness and engagement on the part of the Evangelical Church. But as this discourse is still very restricted to certain institutional spheres, not reaching broader contingent of evangelicals, this work seeks to question and understand how the biblical texts can inspire an Eco(Theo)logical vision to check whether the theological discourse can, in fact, contribute to environmental awareness, presenting the institutional practices of the church into environmental evangelical theological discourse. The research investigated the participation of some Evangelical Christian NGOs, Brazilian Baptist Convention, Baptist Church in Brazil in the city of Cabedelo PB, to improve the quality of life of local communities by encouraging responsible actions from the faithful evangelicals.

Keywords: Eco(Theo)logy; speech; Baptist Church.

\section{Introdução}

O objetivo deste artigo é analisar o discurso teológico ambiental adotado por parte da Igreja Batista a partir da literatura bíblica e teológica e sua aplicação na comunidade evangélica batista e, para isso, recorrer-se-á à Eco(Teo)logia, uma área de estudos que tem, etimologicamente ${ }^{1}$, na Ecologia ${ }^{2}$ e na Teologia ${ }^{3}$, conteúdos essenciais para a sua compreensão e que apontam para a possibilidade de integração entre os discursos científico e religioso, apesar da histórica ruptura operada entre Ciência e Religião.

Neste sentido, este estudo procura fundamentar-se no pensamento de Foucault, em sua análise acerca da arqueologia do saber, por associar a formação de novos campos disciplinares a acontecimentos políticos e econômicos e à origem ou mudanças em instituições. “A arqueologia faz também com que apareçam relações entre as formações discursivas e domínios não discursivos (instituições, acontecimentos políticos, práticas e processos econômicos)" (FOUCAULT, 1987, p. 186).
Embora este autor tenha empregado sua pesquisa arqueológica para enfocar a história da medicina clínica, a partir destes critérios descritivos parece possível aplicar a arqueologia de Foucault para compreender o surgimento da Eco(Teo)logia.

Por meio deste diálogo, a re(ligação) do homem com a criação e com o próprio Criador será discutida, contribuindo para a reflexão sobre a formação de uma nova consciência ecológica no âmbito da igreja local e a possibilidade de, a partir de então, construir novos valores que sejam capazes de recriar as relações sociais em novas bases, desenvolvendo o estímulo à sensibilidade e às vivências emocionais, a abertura à alteridade, a diversidade e a valorização de outros saberes complementares ao saber científico, uma vez que estes apontam para uma articulação multidimensional entre ecologia, educação, política, cultura, economia, ética e tecnologia (LIMA, 2009).

A contribuição da tradição discursiva bíblica na construção de um discurso teológico ambiental foi atualizada com as leituras das tradições da criação e alinhada com as trilhas literárias bíblicas e sua discursivização

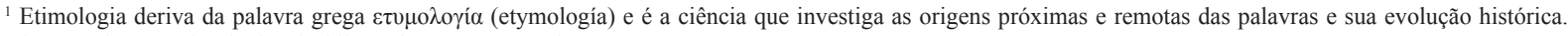
Disponível em: <etimologias.dechile.net/>. Acesso em: abr. 2013.

${ }^{2}$ A Ecologia é a ciência que estuda as relações dos seres vivos entre si e com o ambiente. A palavra ecologia é um neologismo cunhado pelo alemão Ernst Haeckel

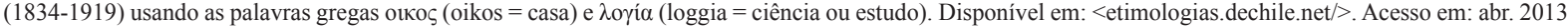

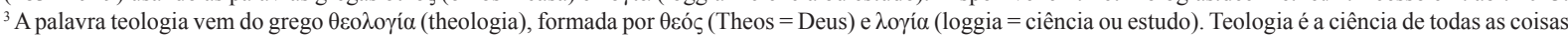
relacionadas a Deus e foi usada por Platão quase quatrocentos anos antes do nascimento de Jesus. Disponível em: <etimologias.dechile.net>/. Acesso em: abr. 2013.
} 
ecológica (LIMEIRA e ANDRADE, 2012) ${ }^{4}$. O que se espera é que este conjunto de leituras de diferentes teólogos, principalmente as narrativas da criação especificadas nos livros de Gênesis, Jó e Salmos e da destruição/ restauração na carta de Paulo aos romanos e no livro de Apocalipse, possam contribuir para a construção de um discurso ambiental.

As escolhas estratégicas de enunciação do discurso da Eco(Teo)logia podem ser analisadas na perspectiva de Foucault (1987, p. 72), identificando menos as escolhas teóricas do que o status, o lugar institucional, os modos de inserção do sujeito falante. Situando o médico e o discurso científico do século XIX, transpondo para o contexto estudado, seriam os teólogos evangélicos e as instituições de onde falam, como a Convenção Batista.

Costa Júnior (2012) $)^{5}$, em sua pesquisa da obra de Jürgen Moltmann, analisa $O$ espírito criador, a ecologia na teologia trinitária, em que o ecológico é tema emergente na produção teológica ocidental. E, na perspectiva de Boff (2003), o discurso teológico ambiental considera a Espiritualidade como um meio para atingir a raiz da crise socioambiental. Entretanto, as produções acadêmicas sobre o tema só se mostrarão relevantes no contexto das ações das igrejas nas comunidades de seu entorno ao buscarem a melhoria da qualidade de vida da população. A partir da compreensão deste discurso, uma re(leitura) da Bíblia e, em especial, das narrativas e tradições da criação, se faz necessária, procurando questionar e compreender como os textos bíblicos podem contribuir para a construção de uma visão eco(teo)lógica, verificando se o discurso teológico pode ou não contribuir para uma conscientização ambiental e, com isso, proporcionar uma visão mais apurada sobre os problemas socioambientais que assolam o planeta (REIMER, 2006), apresentando a ideia de que só a partir de uma nova consciência ecológica da humanidade a crise poderá ser resolvida e para isso é essencial a integração entre os discursos social, científico e literário (HERCULANO, 2000).

Uma visão mais ampla sobre os problemas socioambientais que ameaçam a vida no planeta, ao lado da noção de dever "sagrado" proposta pela Carta da Terra, trouxe muitas adesões nas comunidades religiosas em suas várias vertentes doutrinais. É possível citar o exemplo da Convenção Batista Brasileira (CBB), órgão deliberativo e consultivo das igrejas batistas no Brasil, que, por intermédio da Junta de Educação Religiosa e Publicações (JUERP) e movida por este, entre outros instrumentos de conscientização, tem produzido ampla literatura com foco na resposta à crise ambiental e estes são espaços institucionais que vêm disseminando o saber eco(teo)lógico. As práticas discursivas deste conhecimento passaram a ser exercitadas neste espaço institucional e de lá disseminadas para as igrejas locais.

Com o mesmo nível de comprometimento com a causa ambiental, a Sociedade Bíblica Brasileira (SBB) publicou a "EcoBíblia” ou "Bíblia Verde”, em 2009, uma obra produzida por solicitação do Instituto Gênesis 1:28 - uma ONG Ambientalista Cristã Evangélica - mostrando a relevância do envolvimento da comunidade cristã evangélica quando diz que "o mundo aguarda o mover dos filhos de Deus espalhados por toda a Terra". Outras ONGs cristãs evangélicas têm procurado programar ações que possibilitem o fortalecimento das igrejas no que diz respeito ao cuidado com o meio ambiente. Podemos citar a ONG Cristã Evangélica Internacional “A Rocha" e a ACEV Social, que tem tido papel relevante no desenvolvimento de projetos socioambientais no sertão do Estado da Paraíba, PB.

Segundo Christoffersen (2010, p. 109), as igrejas têm um papel proeminente como disseminadoras do conhecimento, sendo interessante que "atuem mais intensamente, de forma integrada com a ciência, na intermediação política em prol da solução dos problemas ambientais". Para ele, "a moral religiosa ajudaria a reverter os ganhos econômicos advindos da utilização sustentável da biodiversidade genética para as culturas locais".

Além disso, por meio da Igreja e de outras Instituições Cristãs, para melhorar a qualidade de vida da comunidade local, as metas do Desenvolvimento

\footnotetext{
${ }^{4}$ Diálogo entre a tradição bíblica e a construção do discurso teológico ambiental cristão. Horizonte, Belo Horizonte, v. 10, n. 26, p. 603-618, abr./jun. 2012 - ISSN: $2175-5841$.

${ }^{5}$ Tese apresentada ao Programa de Pós-Graduação em Teologia da PUC-Rio como requisito parcial para a obtenção do título de Doutor em Teologia.
} 
Sustentável, quais sejam, a satisfação das necessidades básicas da população (educação, alimentação, saúde e lazer); a solidariedade para com as gerações futuras (preservar o ambiente de modo que elas tenham chance de viver); a participação da população envolvida (todos devem se conscientizar da necessidade de conservar o ambiente e fazer cada um a parte que lhe cabe para tal); a preservação dos recursos naturais (água e oxigênio); a elaboração de um sistema social garantindo emprego, segurança social e respeito a outras culturas (erradicação da miséria, do preconceito e do massacre de populações oprimidas, como, por exemplo, os índios); e a efetivação dos programas educativos, poderiam ser atingidas.

\section{Eco(Teo)logia: uma visão multidimensional}

Se considerada sob a perspectiva etimológica, investigando as origens próximas e remotas das palavras e sua evolução histórica, a Eco(Teo)logia terá, conceitualmente, a ideia de oukoৎ $($ oikos $=$ casa $)+\theta$ có $\varsigma($ Theos = Deus $)+\lambda$ oүí $\alpha($ loggia = ciência ou estudo $)$, ou seja, este neologismo poderá ser definido como a ciência ou o estudo de todas as coisas relacionadas a Deus e à sua casa (criação - acréscimo nosso).

Do ponto de vista acadêmico, a criação do curso Ciências das Religiões em nível de graduação, mestrado e doutorado, em diversas universidades do país e do mundo, possibilitou algumas conexões entre a religião e diferentes ciências, entre elas a Teologia e a Ecologia, fazendo com que a Teologia pudesse ser reconhecida como uma disciplina ${ }^{6}$ que aborda a dimensão da verdade num campo em que o conhecimento científico é por natureza conjectural e passível de ser superado. De acordo com Foucault (2009, p. 36), "a disciplina é um princípio de controle da produção do discurso".

Considerando que, "para pertencer a uma disciplina, uma proposição deve poder inscrever-se em certo horizonte teórico" (FOUCAULT, 2009, p. 33) e que "todo sistema de educação é uma maneira política de manter ou de modificar a apropriação dos discursos com os saberes e os poderes que eles trazem consigo" (FOUCAULT, 2009, p. 43-44), a Eco(Teo)logia começa a emergir como uma disciplina institucionalizada, procurando integrar o discurso científico ao teológico, por meio das relações entre Ciências Naturais e Espiritualidade.

Sob a perspectiva teológica, entretanto, para alguns estudiosos, a Eco(Teo)logia é uma forma de teologia construtiva que incide sobre a inter-relação da religião e da natureza, em particular à luz das preocupações ambientais, assumindo que existe uma relação entre a visão do mundo espiritual e da degradação da natureza, por entender que as relações dos seres vivos entre si e com o ambiente devem ser estudadas como uma ciência que relaciona todas as coisas a Deus.

Em outra variável, no entanto, devido ao forte apelo do planeta por redenção, o discurso sobre a missão integral da Igreja surge com um novo formato: Eco(Teo) logia que, a partir de diretrizes ecológicas, entende que a relação entre evangelização e ação social se justifica ante a relevância do tema e da responsabilidade profética da Igreja.

De acordo com Murad (2009, p. 277):

o elemento diferenciador da teologia ecológica ou ecoteologia não é fazer do meio ambiente o objeto da reflexão iluminada pela fé. A ecoteologia, numa relação de continuidade e ruptura com a grande tradição da Igreja, deve necessariamente articular, no interior de seu discurso, a criação em Cristo no Espírito, a história, a encarnação, a redenção e a consumação.

O que se compreende é que, segundo Murad (2009), neste primeiro momento, há certa sobreposição de elementos, sem ainda alcançar a fecundação dos saberes, uma vez que alguns autores utilizam a expressão "ecoteologia" ou "teologia ecológica" para designar o resultado deste profícuo diálogo, que traz elementos novos tanto para a teologia quanto para a ecologia.

O termo Eco(Teo)logia será utilizado, neste tópico, entendendo que ele apresenta várias limitações e apresentando algumas considerações que são relevantes para

\footnotetext{
${ }^{6}$ Conjuntos de enunciados que emprestam sua organização a modelos científicos, que tendem à coerência e à demonstratividade, que são recebidos, institucionalizados, transmitidos, e às disciplinas ensinadas como ciências (FOUCAULT, 1972, p. 216).
} 
conhecê-la: a Espiritualidade genuína está ligada à vida; o planeta Terra é a casa da humanidade; é preciso cuidar dele como uma casa comum; a falta de preocupação com a Terra mostra falta de amor ao próximo; a falta de amor ao próximo significa falta de amor a Deus. Então, à luz desta perspectiva, quanto melhor a relação do homem com o Criador, melhor será a relação com o próximo e com a criação.

A Eco(Teo)logia recorre ao texto bíblico "E viu Deus tudo quanto tinha feito, e 'eis que era muito bom'; e foi a tarde e a manhã, o dia sexto", de Gênesis 1:31. Sobre este texto, Pfeiffer (1999, p. 5) diz que "quando o Senhor olhou para o resultado final de seus atos criadores, expressou deleite peculiar e satisfação extrema [...] A satisfação do Criador aqui se expressa em linguagem concisa, ainda que vívida".

O consenso entre os discursos eco(teo)lógicos, em busca de uma epistemologia ambiental, segundo Andrade (2008), está na necessidade de garantir e melhorar a qualidade de vida desta e das futuras gerações. Para Lopes (2010), o Cristianismo, enquanto fiel às suas raízes bíblicas, tem condições de oferecer uma visão de mundo que permite enfrentarmos de forma coerente e lógica as questões ecológicas de hoje, mas, para que isto aconteça, é necessário que a Eco(Teo)logia seja vista, conforme afirma Murad (2009), não simplesmente como uma Teologia da criação com tons verdes, mas como um campo de estudos que apresenta ligações estreitas e complexas entre a criação do cosmos e seu processo evolutivo, o surgimento dos seres humanos no nosso planeta, a história da revelação divina com suas etapas, a encarnação do Filho de Deus, a inauguração do Reino de Deus em Jesus, sua morte redentora e a ressurreição como primícias da nova criação, sem perder de vista que a história humana e seu destino final devem ser compreendidos em íntima relação com o ecossistema, considerando a Espiritualidade e a ética.

O ambiente deve ser visto como o lugar onde pessoas estabelecem relações considerando princípios de Ética, ou seja, normas morais e comportamentais que visam ao conhecimento em defesa da vida e cabe ao homem a conversão de hábitos cotidianos e políticos, privados e públicos, culturais e espirituais (PELIZZOLI, 2003).
A conservação e a preservação do planeta devem fazer parte de um conjunto de ações prioritárias em que o homem, como única espécie dotada de uma moral/ consciência de responsabilidade da sociedade, precisa estar envolvido a fim de garantir e melhorar a qualidade de vida desta e das futuras gerações (ANDRADE, 2008). As religiões tiveram e têm participação importante neste processo de emergência da nova consciência ecológica por poderem conduzir programas em nível mundial e a participação ativa de segmentos religiosos nos fóruns específicos no contexto da ONU o podem confirmar (REIMER, 2011). Ou seja, por meio da Ética, garantir a sustentabilidade, apesar de toda a diversidade de posições e práticas envolvidas na ética, na natureza e na teologia (PELIZZOLI, 2003).

É possível apreender, diante do exposto e de acordo com Stott (2011, p. 45), que uma mudança de valores morais, éticos, culturais e espirituais na humanidade poderia propiciar três tipos fundamentais de relacionamento: do homem com o Criador, "pois ele fez o homem à sua própria imagem"; entre si, "pois a raça humana é plural desde o princípio"; e "para com a boa terra e as criaturas sobre as quais ele os estabeleceu", o que culmina com o cuidado com o meio ambiente.

Só a partir de uma nova concepção ética, segundo Reimer (2006), o homem poderia incorporar as diversas vertentes das preocupações ecológicas: ambiental, social, mental e integral. Para Pelizzoli (2003), é urgente a construção de novas relações humanas com a natureza e isto deve ser feito a partir do diálogo, do questionamento e da construção de várias interfaces que possibilitem uma postura humana de defesa e sobrevivência, movidas por ações tendo em vista as consequências já diagnosticadas pela ciência, uma vez que, se o homem é o causador da crise ambiental, é também o responsável e tem o dever de reverter a degradação imanente.

O grande obstáculo para o avanço das mudanças de consciência no que diz respeito às ações ecológicas é a ética predominante na sociedade industrial. Entretanto, quanto mais informações sobre a crise ambiental e suas consequências forem divulgadas, e quanto mais em educação ambiental for investido, maior será o nível de consciência ecológica na sociedade, que passa a entender o dever de impedir o dano causado ao meio ambiente e de proteger o direito das pessoas, cuidando 
da comunidade da vida com compreensão, compaixão e amor (LIMA, 2009).

A Espiritualidade, que é universal, é apontada por Boff (2003) como uma alternativa urgente que emerge da religião por meio de um processo de conscientização, já que o homem tem em sua alma sonhos salvacionistas movidos pela esperança de que, com a sua experiência, possa provocar uma mudança de paradigmas socioeconômicos que possam trazer benefícios para as questões ambientais e a humanidade. m conformidade com Lopes (2010), precisa ter em sua agenda de compromissos a preocupação constante sobre os efeitos econômicos e ambientais do aquecimento global e o Cristianismo.

Considerando os textos bíblicos a partir da concepção exegética de Cullmann, House, Marshall, Reimer (2006, 2011) e Wolff, é possível notar que uma abordagem teológica de interface socioambiental está sendo construída levando em conta o papel criador de Deus, que age dentro da história humana, num mundo ainda em construção por Deus, sendo necessário, segundo Murad (2009), um tempo de maturação até chegar ao nível do diálogo interdisciplinar e transdisciplinar.

\section{Tradição bíblica: uma abordagem de interface socioambiental}

Para a análise discursiva, o corpus da pesquisa foi definido a partir da representação de alguns excertos sobre as tradições da criação, sob os prismas judaico e cristão, encontrados nas narrativas da criação no livro de Gênesis, nas narrativas dos livros de Jó e Salmos no Velho Testamento, na carta do apóstolo Paulo aos Romanos no Novo Testamento e nas narrativas da destruição/ restauração no livro de Apocalipse, perpassando os textos vetero e neotestamentários.

O discurso teológico ambiental considera a Espiritualidade ${ }^{7}$ como um meio para, segundo Boff (2003), atingir a raiz desta crise, uma vez que a inteligência intelectual, emocional e espiritual concedida por Deus no ato da criação colocou, na alma humana, o desejo de cuidar da vida em sua excelência. A partir de uma re(leitura) da Bíblia, segundo Reimer (2006), em especial as narrativas e tradições da criação e sua apropriação pelo discurso teológico, é possível questionar e compreender como os textos bíblicos podem contribuir para a construção de uma teologia de inspiração ecológica.

Os estudiosos observam que a diferença principal entre Gênesis e relatos babilônicos e egípcios sobre a criação é a insistência israelita no monoteísmo. O monoteísmo na criação significa que Deus não conhece limites na natureza nem está restrito a determinado ponto geográfico. Para a tradição judaico-cristã, se existe um só Deus, então Ele deve ser o responsável por cada ato criador. A literatura bíblica, segundo House (2005), é um referencial para a tradição judaico-cristã de maneira geral e universal. Seu texto transcende os limites espaço-temporais e contribui, com suas narrativas e tradições da criação, de maneira especial, para o estabelecimento de uma cultura voltada para Deus como Criador de todas as coisas visíveis e invisíveis.

Existem outras concepções acerca da criação. Dentre elas está a Cabala, que para alguns é a base para a tradição da criação feita pelo judaísmo e que descreve um sistema complexo denominado Cosmogênese; a Mitologia do Egito, que diz que a terra surgiu do Nilo e antes de todas as coisas não havia senão trevas e "água primordial"; a Mitologia da Grécia, para a qual a criação surgiu da união do Céu e da Terra, e ainda muitas outras. Entretanto, a despeito das religiões serem politeístas ou monoteístas, que considerem a pluralidade de deuses ou a singularidade de Deus, são unânimes em reconhecer, do ponto de vista ético, a responsabilidade do homem para com a problemática da crise ambiental.

A tradição judaico-cristã considera, entretanto, que a Bíblia oferece perspectivas, atitudes e valores que

\footnotetext{
${ }^{7}$ Espiritualidade vem de espírito. Para entendermos o que seja espírito, precisamos desenvolver uma concepção de ser humano que seja mais fecunda do que aquela convencional, transmitida pela cultura dominante. Esta afirma que o ser humano é composto de corpo e alma ou de matéria e espírito. Ao invés de entender essa afirmação de uma forma integrada e globalizante, entendeu-a de forma dualista, fragmentada e justaposta. Assim, surgiram os muitos saberes ligados ao corpo e à matéria (ciências da natureza) e os vinculados ao espírito e à alma (ciências do humano). Perdeu-se a unidade sagrada do ser humano vivo, que é a convivência dinâmica de matéria e de espírito entrelaçados e inter-retroconectados. Disponível em: <http://www.leonardoboff.com/site/vista/outros/espiritualidade.htm>. Acesso em: abr. 2013
} 
dizem respeito à relação entre a humanidade e todo o mundo criado. Mais especificamente, que esta oferece uma base para avaliar a retórica ecológica em que é possível desenvolver uma perspectiva bíblica do meio ambiente e do ser humano em todas as suas dimensões - a sua relação e dependência da criação e sua relação e dependência de Deus. Segundo Stott (2011, p. 44), "a Bíblia aponta o caminho ao fazer duas afirmações fundamentais: 'Ao Senhor pertence a terra' (S1 24.1) e 'a terra, deu-a ele aos filhos dos homens' (S1 115.16)".

Embora as tradições literárias do livro de Gênesis sejam o grande norteador de toda exegese bíblica sobre a ética da criação do mundo e sobre a responsabilidade humana sobre os seus cuidados, outros textos bíblicos, incluindo as narrativas deuteronômicas, proféticas, poéticas, epistolares e os evangelhos, são mencionados com o objetivo de reconciliar o texto bíblico em uma unidade integral.

De acordo com Cullmann (1996, p. 13), os primeiros capítulos de Gênesis:

descrevem duas progressões antagônicas: primeiro, a ordenada criação realizada por Deus, até o seu clímax no homem como ser responsável e abençoado; e depois a obra desintegradora do pecado, até o seu primeiro grande anticlímax no mundo corrupto do dilúvio, e seu segundo anticlímax na loucura de Babel.

Na opinião de Pfeiffer (1999, p. 5), ao comentar Gênesis 1:28, o homem "tinha de ser o representante e mordomo responsável de Deus sobre a terra, fazendo a vontade do seu Criador e cumprindo o propósito divino". Em Gênesis 2:15 (p. 7), o mesmo diz que "O trabalho do homem neste jardim era o de exercer domínio servindo - uma boa combinação. As obrigações provavelmente eram rigorosas, mas agradáveis".

Kidner (2004, p. 33), ao analisar o homem na sociedade na teologia de Gênesis, diz que "um importante elemento da vocação original do homem consistia em 'cultivar' e 'guardar' seu meio ambiente imediato, e dominar, bem como encher a terra". Os binômios sujeitar-dominar e cultivar-guardar, de Gênesis 1:28, "E Deus os abençoou, e Deus lhes disse: Frutificai e multiplicai-vos, e enchei a terra, e sujeitai-a; e dominai sobre os peixes do mar e sobre as aves dos céus, e sobre todo o animal que se move sobre a terra", e Gênesis 2:15, "E tomou o SENHOR Deus o homem, e o pôs no jardim do Éden para o lavrar e o guardar", segundo Reimer (2006), têm desempenhado um papel importante na autocompreensão dos homens no mundo e têm, na leitura de Boff (2003), o sentido de cuidado e não de dominação. O texto ordena que os humanos cuidem de toda a criação, não destruindo a natureza criada por Deus, mantendo suas bases de sustentação e o seu próprio ciclo de vida.

Comentando a primeira parte do versículo 28 de Gênesis 1 "E Deus os abençoou”, Kidner (2004, p. 49) diz que "abençoar não é só conferir uma dádiva, mas também uma função e fazê-lo com ardoroso interesse". Com relação a Gênesis 2:15, Kidner (2004, p. 57) declara que "há um trabalho próprio para o ser humano à espera dele, para o corpo e para a mente". Deus delegou ao homem responsabilidades morais e éticas para lavrar e guardar o planeta como um patrimônio desta e das futuras gerações.

Os capítulos 1 e 2 de Gênesis apresentam o Deus que cria, na concepção de House (2005, p. 76-78), e a ordem criada é exibida como "o resultado da atividade intencional da parte do Deus único". Cada criatura tem seu lugar neste mundo, com dignidade própria dada por Deus, assegurando que toda a criação é boa, complexa e apropriada para seu propósito. Os seres humanos ocupam um lugar único entre as criaturas. Feitos à imagem e semelhança de Deus, recebem a ordem de dominar e subjugar a terra. Semelhantemente a Deus, os seres humanos têm a capacidade de tomar decisões que afetam positiva ou negativamente a terra e seus moradores. Receberam a terra toda para sustentá-los e não o contrário, contudo, é óbvio que o domínio sábio será necessário para que da terra os seres humanos extraiam sustento.

Os princípios teológicos, conhecidos como Mandato Cultural e Mordomia Cristã, retirados das Escrituras Sagradas, têm sido reiteradamente cooptados para legitimar um domínio utilitarista dos humanos sobre a criação. De acordo com Stott (2011, p. 46), “A culpa pela irresponsabilidade ambiental tem sido injustamente posta em Gênesis 1". Diante de novos desafios na lógica de um pensamento ecológico, é importante redescobrir e reler esse texto. Segundo Reimer (2006), esta leitura não deve ser antropocêntrica, teocêntrica ou egocêntrica, 
mas, ecocêntrica, isto é, tomando a casa da criação e suas introrretrorrelações como ponto de partida e referencial hermenêutico na leitura deste texto.

A palavra de bênção concedida aos seres humanos no versículo 28 de Gênesis, segundo Wolff (2007, p. 156), "se distingue basicamente daquela dos peixes e das aves no versículo 22 pela circunstância de que, depois da autorização para se multiplicar, é confiado aos seres humanos o domínio sobre a terra e principalmente sobre todos os animais". De acordo com Wolff (2007, p. 250251), "a natureza da administração humana do mundo é uma superioridade incondicional e [...] o ser humano está autorizado a fazer transformações úteis".

O Escrito Sacerdotal, segundo Wolff (2007, p. 339), exprime que "em relação a todas as outras coisas criadas além do ser humano, seu destino é igualmente claro: dominar" e faz isso "do modo mais incisivo ao definir que a intenção de Deus, ao criar o ser humano segundo a sua imagem, seria para que ele governasse a terra".

Em Gênesis 2:15, Wolff (2007, p. 202) "acentua que o trabalho já é incumbência do ser humano como criatura" e acrescenta que "Javé leva o ser humano para lá (o jardim, acréscimo nosso), a fim de que ele o cultive e proteja" indicando "os dois lados de toda a atividade profissional do ser humano: 'cultivo como servidor' e 'vigiar protetor"'. Além disso, para ele, "a sujeição do mundo não deve trazer perigo ao ser humano, como acontece em proporções ameaçadoras devido à poluição do meio ambiente" (2007, p. 253).

Ao sintetizar a posição de alguns teólogos do discurso eco(teo)lógico, apresentados nos parágrafos anteriores, pode-se perceber que ambos releem a tradição da criação reiterando princípios como Mandato Cultural e Mordomia Cristã, respectivamente encontrados em Gênesis 1:28 e 2:15, para defender que uma das faces da adoração incluía o serviço que, neste caso, vinha da responsabilidade moral e ética de cuidar e guardar o planeta e não para legitimar o domínio utilitarista dos humanos sobre a natureza.

Segundo House (2005), os livros sapienciais de Jó dizem que somente Deus possui a compreensão da sabedoria porque só ele criou forças misteriosas como o vento, água, relâmpagos e trovões (Jó 28:25-26) e em Provérbios 8:22-36 diz que Yahweh usou sabedoria infinita na criação. Reimer (2006) concorda que o livro de Jó constitui bom espaço para uma leitura ecológica. Na condição de marginalidade de vida, o questionamento de Jó a Deus sobre sua capacidade de gerenciar a criação desencadeia uma resposta divina (Jó 38-42) em que se descortina toda a complexidade das relações no complexo espaço da criação.

Na concepção de Wolff (2007, p. 238-239), os salmos mostram de que modo Javé é o fundamento da esperança, "A nossa alma espera no SENHOR; ele é o nosso auxílio e o nosso escudo" (Salmos 33:20); acentuam que a confiança se fundamenta na promessa e na realização da mesma, "Aguardo ao SENHOR; a minha alma o aguarda, e espero na sua palavra" (Salmos 130:5); e mostram como o temor de Deus e a esperança em Javé podem se tornar conceitos paralelos que se apoiam mutuamente, "O SENHOR se agrada dos que o temem e dos que esperam na sua misericórdia” (Salmos 147:11).

No Novo Testamento, Jesus é o referencial, o modelo que possibilita seguir os seus passos, estar n'Ele conforme o apóstolo Paulo diz aos coríntios: "Assim que, se alguém está em Cristo, nova criatura é; as coisas velhas já passaram; eis que tudo se fez novo" (2 Coríntios 5:17). As Escrituras dizem que a relação de Jesus com a criação está no fato de que tudo foi criado por ele e para ele, conforme Colossenses 1:16, "Porque nele foram criadas todas as coisas que há nos céus e na terra, visíveis e invisíveis, sejam tronos, sejam dominações, sejam principados, sejam potestades. Tudo foi criado por ele e para ele" e Efésios 1:9-10 "Descobrindo-nos o mistério da sua vontade, segundo o seu beneplácito, que propusera em si mesmo, de tornar a congregar em Cristo todas as coisas, na dispensação da plenitude dos tempos, tanto as que estão nos céus como as que estão na terra" e Apocalipse 3:14, "E ao anjo da igreja que está em Laodiceia escreve: Isto diz o Amém, a testemunha fiel e verdadeira, o princípio da criação de Deus".

Em conformidade com Cullmann (1996, p. 66-67), a primeira parte da carta de Paulo aos Romanos tem uma natureza dogmática e, particularmente, o capítulo 8 , que, de acordo com um plano sistemático, aborda a libertação pelo Espírito Santo e, em conformidade com Marshall (2007, p. 278-279), Paulo desenvolve a ideia do contraste entre o sofrimento presente e a glória futura e põe a questão no contexto do mundo perecível e decaído 
que será restabelecido em seu devido tempo por Deus. A renovação do mundo é uma parte integrante da esperança na tradição judaico-cristã e, de acordo com Wolff (2007, p. 241), “a esperança para a qual a Bíblia está encaminhada promete uma nova criação que transcende radicalmente as possibilidades próprias do ser humano".

No excerto do artigo intitulado "Celebração da vida: diálogo com a Teologia Ecológica de Jürgen Moltmann", publicado pela PUC-Rio, Costa Júnior considera que "A teologia ecológica deve ser teologia reagente, isto é, deve reagir perante todas e quaisquer concepções de Deus e do seu relacionamento com o mundo que, de algum modo, contribuam para o fortalecimento da ideia do ser humano dominador". Assim, sob a mesma perspectiva de Boff (2003) e Reimer (2006), para Costa Júnior "essa teologia deve atentar para o grito e o gemido de dor do mundo (Romanos 8:22) por causa das constantes agressões que sofre" (PUC-Rio, 2013).

Quando Paulo argumenta sobre a criação, ele relata o que, teologicamente, pensa estar acontecendo com os cristãos de Roma. A natureza criada aguarda, com grande expectativa, que os filhos de Deus sejam revelados, submetida à futilidade não pela sua própria escolha, mas por causa da vontade daquele que a sujeitou, na esperança de que a própria natureza criada será libertada da escravidão da decadência em que se encontra para a gloriosa liberdade dos filhos de Deus. Segundo Stott (2011, p. 46), "é plausível, portanto, que o plano de Deus de restauração inclua não apenas a nossa reconciliação com Deus e com o próximo, mas também, de alguma maneira, a libertação da criação que geme".

A crise ecológica atual tem sido explorada, segundo Stott (2011), considerando o "crescimento populacional acelerado do mundo" (p. 48), "a depleção dos recursos da terra” (p. 48), "o descarte do lixo” (p. 48) e "a mudança climática” (p. 49). Para ele, a reflexão sobre esses quatro riscos ambientais torna impossível não perceber que todo o nosso planeta está ameaçado (p. 50). Na verdade, as razões dessa crise são bastante conhecidas nesse processo de expansão da civilização tecnológica: desmatamentos, fim de espécies vegetais e animais, envenenamento do ar e do solo, iniciando um processo de desertificação. Continua dizendo que devemos nos relacionar com a terra evitando: "a deificação da natureza" (p. 45) e "a exploração exaustiva da natureza" (p. 46); por meio da "cooperação com Deus" (p. 46). (grifos do autor)

O texto de Romanos 8:22, para Reimer (2006), transmite a ideia de que toda a natureza criada geme como em dores de parto. Paulo está dizendo que, quando a humanidade for levantada dentre os mortos, então a natureza também será redimida, porque o sangue do cordeiro redentor, Jesus Cristo, remirá o homem e a natureza e que a criação, que está sofrendo, tem a expectativa de que o poder de Cristo a liberte do sofrimento e das amarras da opressão. Isso remete para a noção de nova criação e adquire significado antropológico e dimensão cosmológica.

Segundo Wolff (2007, p. 233), a expectativa do futuro faz parte da essência do ser humano, entretanto, ele não dispõe do futuro, porque Javé é sua única esperança e a dispensa como dádiva ao ser humano. $\mathrm{O}$ autor do livro de Apocalipse anuncia que esta esperança já começou a se realizar: "Eu vi um novo céu e uma nova terra" (Apocalipse 21:1). O propósito do livro de Apocalipse, segundo Marshall (2007, p. 483), é "preparar o povo de Deus para o difícil futuro que o espera e lançar um apelo evangelístico àqueles que ainda não responderam ao testemunho cristão". Os capítulos 21 e 22 de Apocalipse anunciam, segundo Marshall (2007, p. 482), a descrição da "nova Jerusalém (em substituição à antiga), onde Deus morará com seu povo". A análise que Marshall (2007, p. 487-488) faz "é que a cidade localiza-se numa nova terra e não no céu, e uma vez que Deus e o Cordeiro estão na cidade, parece que a terra e o céu se uniram".

Uma análise, na perspectiva da leitura ecológica dos discursos bíblicos da criação, da destruição e da restauração, perpassando o Velho e o Novo Testamento, com base nos autores apresentados, aponta para a esperança da renovação, que encontra sua razão de ser na cruz, onde Jesus reconciliou toda a natureza criada.

Conforme Reimer (2006), num contexto sócio-histórico hostil, as comunidades cristãs reinterpretam tradições profético-apocalípticas dentro de um horizonte histórico-salvífico. A partir de um contexto de opressão política, de exploração econômica e de discriminação religiosa - o ressurgir do caos original - que o Apocalipse faz também sua re(leitura) do Gênesis. A expectativa da salvação vem da certeza de que Deus pode recriar todas as coisas. 
A igreja cristã precisa ser preparada para compreender a sua responsabilidade individual e coletiva diante da infinitude de Deus e da finitude do homem e se importar o bastante para, junto à sua comunidade, priorizar, identificar e então tentar resolver alguns dos importantes problemas sociais de sua própria localidade, construindo pontes e se envolvendo nos dilemas reais dos homens, se engajando por meio do serviço integral a exaltar o Deus da criação, sendo participante dessa diaconia ecológica, não se conformando com o estado atual das coisas, mas rompendo com ele numa visão bíblica criacional e serviço (STOTT, 2010).

\section{O desafio de dialogar: integrando o discurso eco(teo)lógico à prática institucional cristã evangélica}

A expectativa desta análise é fornecer dados que possam criar possibilidades de compreender a maneira pela qual os teólogos cristãos estão construindo uma nova epistemologia ambiental, a partir da integração dos discursos eco(teo)lógicos, por meio do diálogo com instituições não governamentais e eclesiásticas.

De acordo com Schaeffer (1976), é preciso verificar como a Igreja Cristã, crendo nas verdades decorrentes da re(leitura) ecológica das Escrituras Sagradas judaico-cristãs, pode aplicá-las de modo prático e global para minimizar os efeitos destrutivos previstos pela Ecologia porque, a menos que exista um relacionamento ético entre Deus e os homens, é impossível que as pessoas ajam como representantes ou mordomos de Deus na Terra.

O Cristianismo, cujas bases epistemológicas estão fundamentadas nas Escrituras Sagradas judaico-cristãs, de acordo com Lopes (2010), contribui para a formação de uma consciência ecológica quando ensina que o homem é responsável, diante de Deus, pelo uso racional e correto do mundo e da criação e que a doutrina reformada da fé cristã provê os elementos morais, espirituais e éticos para que possamos fazer ecologia de forma coerente e integral.

Historicamente, a igreja tem perdido, conforme César (2012), cada vez mais a percepção da relação entre o Evangelho e as questões ambientais. Aliás, alguns autores têm sugerido que o principal motivo da crise ecológica é a influência da religião judaico-cristã, que coloca o homem numa posição diferenciada e superior em relação aos demais seres vivos, com papel de dominador e controlador da natureza. Ou seja: enquanto a igreja pensa que não tem nada a ver com a crise ambiental global, muitos pensadores a acusam de ser sua principal causadora.

Para viabilizar o diálogo entre discurso e prática discursiva, foram escolhidas as ONGs Cristãs Evangélicas denominadas: Instituto Gênesis 1:28, A Rocha Brasil e ACEV Social, cujas ações têm se mostrado relevantes no âmbito do Brasil e na Paraíba, particularmente no sertão, visando ao desenvolvimento e à melhoria da qualidade de vida de comunidades cristãs e não cristãs, e a Convenção Batista Brasileira, que, institucionalmente, tem procurado envolver igrejas a ela convencionadas em campanhas de conscientização nas diversas esferas da problemática ambiental para a formação de uma nova consciência ecológica.

As ONGs cristãs são redes e agências que enfocam aspectos específicos da missão mais ampla da igreja. Elas podem trabalhar juntamente com a igreja local, complementando a sua missão. O mesmo pode ser feito no âmbito regional ou nacional por intermédio das denominações eclesiásticas. As ONGs também poderão criar condições para que novas igrejas locais sejam formadas nas regiões onde trabalham.

A visão da TEARFUND, uma ONG Cristã Evangélica Internacional, por exemplo, é ver milhões de pessoas livres da pobreza material e espiritual por meio de uma rede de igrejas locais. A partir desta visão, desenvolvem uma grande variedade de recursos para ajudar na mobilização da Igreja. Para Castells (1999), a principal característica da rede é que ela é uma estrutura aberta, em constante expansão, o que se dá pela integração de novos nós, desde que compartilhem os mesmos códigos, como por exemplo, um conjunto de valores ou um objetivo, e isso vale para a economia, a cultura, para todos os setores e formas de organização da sociedade.

O Instituto Gênesis 1:28 é a organização que tem como missão primordial cooperar e promover o desenvolvimento social, ambiental e espiritual sustentável, por meio do aprendizado, diálogo e ação, informando, em seu portal eletrônico, sobre os avanços das ações em 
prol da proteção e preservação do meio ambiente, em quaisquer que sejam seus âmbitos.

Outro trabalho relevante que precisa ser citado é o da ONG “A Rocha Internacional”, uma organização de conservação da natureza e educação ambiental, de inspiração cristã, sem fins lucrativos. A primeira iniciativa foi desenvolvida em Portugal, com a criação do primeiro campo de estudo. A Rocha é atualmente uma família de projetos com trabalhos na Europa, Oriente Médio, África, Américas do Norte e Sul, Ásia e Oceania. Os projetos da Rocha são caracteristicamente feitos a partir do intercâmbio, com uma forte ênfase na partilha comunitária e foco em ciência, investigação, conservação, prática e educação ambiental.

Os projetos de A Rocha Brasil são desenvolvidos com base em cinco compromissos: 1. Cristão - cremos na revelação bíblica de que Deus criou e ama o mundo; 2. Conservação - baseada na investigação, planejamento e execução de projetos científicos; 3. Comunidade - é fundamental relacionar-se com Deus, uns com os outros e com toda a criação, bem como envolver as comunidades locais nesse processo e buscar nós mesmos sermos bons exemplos de comunidade; 4 . Transcultural - nenhuma cultura apresenta todas as soluções para os problemas ambientais; por isso a necessidade de compartilhar ideias e práticas entre países e culturas distintas; 5 . Cooperação - somar esforços, trabalhar em rede e estabelecer parcerias com outras organizações e indivíduos que partilham dos objetivos ambientais é fundamental, independentemente de suas crenças.

Por último, a ACEV Social é apresentada como uma ONG que gerencia o Programa Sertão Sustentável com o Programa de Desenvolvimento Comunitário Rural com vários projetos. Dentre as ONGs apresentadas, esta é a única que tem o apoio eclesiástico da Ação Evangélica - uma igreja e missão brasileira com a visão de viver a missão integral de Jesus Cristo no nordeste do Brasil, especialmente focalizando seu trabalho de desenvolvimento comunitário cristão nas regiões semiáridas dos sertões. Esta ONG tem como missão ser facilitadora do desenvolvimento humano integral e socioambiental do nordeste brasileiro.

A partir da apresentação das ações desenvolvidas por estas três ONGs em seu esforço para proteger, preservar e garantir o desenvolvimento com sustentabilidade nas comunidades onde estão inseridas, é interessante notar que o discurso bíblico apropriado pelo discurso teológico ambiental tem motivado a participação da sociedade na busca pela melhoria de suas condições de vida. É perceptível que o que move o trabalho destas ONGs é o esforço para, como cristãs evangélicas, conceber o planeta como criação de Deus e responsabilidade de cada cidadão o seu cuidado, principalmente o cidadão cristão.

Dando continuidade ao desafio de integrar o discurso teológico à sua prática ecológica, é interessante citar o trabalho da $\mathrm{CBB}$ - órgão máximo da denominação batista no Brasil e a maior convenção batista da América Latina -, representando e servindo às igrejas batistas brasileiras como sua estrutura de integração e seu espaço de identidade, comunhão e cooperação, definindo o padrão doutrinário e unificando o esforço cooperativo dos batistas do Brasil.

Sobre o trabalho da CBB, em sua atuação junto às igrejas, Foucault diria que "em toda a sociedade, a produção do discurso é, ao mesmo tempo, controlada, selecionada, organizada e redistribuída por certo número de procedimentos que têm por função conjurar seus poderes e perigos" (FOUCAULT, 2009, p. 8-9).

A CBB, ao longo de sua história, tem se mantido fiel ao cumprimento do Mandato Cultural (Gênesis 1:28) e do princípio de Mordomia Cristã (Gênesis 2:15), incentivando as igrejas a ela convencionadas a cuidar, proteger e preservar o meio ambiente. Movida por seu compromisso com a missão integral da igreja, a CBB, por intermédio da Junta de Educação Religiosa e Publicações (JUERP), tem produzido ampla literatura, dentre elas as revistas: Educador; Compromisso; Atitude; Diálogo e Ação; Vivendo, Crescendo e Aprendendo, cujo objetivo foi, no ano de 2011, focalizar uma resposta para a crise ambiental, com vistas a atender ao tema do ano da CBB: Vida Plena e Meio Ambiente.

Além das publicações da JUERP, a União Feminina Missionária Batista do Brasil (UFMBB), editora da Revista Visão Missionária, tem produzido artigos que contribuem para a formação de uma nova consciência em meio às mulheres cristãs batistas em ação por todo o Brasil, atuando nas áreas espiritual, pessoal, social e ambiental. De acordo com Foucault, é preciso "estar pronto para acolher cada momento do discurso em sua irrupção como acontecimento" (FOUCAULT, 1972, p. 36). 
Durante a sua última sessão, como resultado das discussões, os participantes da $91^{\text {a }}$ Assembleia da CBB aprovaram a "Carta de Niterói", documento por meio do qual os batistas brasileiros assumiram uma posição clara em prol da preservação da criação de Deus e estabeleceram marcos de um novo momento de reflexão sobre a atuação pastoral da igreja no meio ambiente. Esta carta abriu espaço para a igreja refletir sobre a sociedade em que está inserida e para apresentar propostas para amenizar o problema, contribuindo para atenuar os dilemas ambientais.

Segundo Schaeffer (1976, p. 63), "Deus trata sua criação com integridade: cada coisa segundo a sua espécie, cada coisa na forma como a fez. Se Deus trata sua criação assim, não deveríamos nós tratar os nossos companheiros de criação com igual integridade?"

Depois de analisar o que, institucionalmente, foi realizado, pela CBB, com vistas ao tema do ano de 2011, Vida Plena e Meio Ambiente, é interessante verificar a repercussão destas ações dialogando com algumas igrejas evangélicas batistas do Brasil e, particularmente, da cidade de Cabedelo, $\mathrm{PB}$, onde o diálogo entre teoria e prática será observado.

$\mathrm{Na}$ Paraíba, alguns eventos puderam ser registrados. Na programação da Semana em Foco da Organização Mulher Cristã em Ação (MCA), em 2011, da Primeira Igreja Evangélica Batista do bairro do Jardim Veneza (PIEBJV), em João Pessoa, PB, o tema escolhido foi "Com vida plena preservemos o mundo" e a divisa, ou seja, o texto bíblico escolhido, foi Romanos 8:22, que diz "Porque sabemos que toda criação geme e está juntamente com dores de parto até agora". O assunto foi abordado tentando encontrar pontos de encontro entre os discursos da literatura bíblica e científica.

No $9^{\circ}$ aniversário da Congregação Evangélica Batista em Cidade Verde (CEBCV), no bairro das Indústrias, a Organização MCA escolheu o hino "Apocalipse", cuja proposta está versada na temática ambiental. Esta não foi a primeira experiência ecológica da CEBCV: a mesma participou do evento marcado como a Hora do Planeta em março de 2011, fazendo um jantar à luz de velas com os casais da Congregação. Além disso, como incentivo, a organização MCA organizou um culto festivo especial para comemorar o Dia Internacional da
Mulher e presenteou cada mulher com um artesanato feito com copinhos descartáveis.

Foram observadas ações práticas e de conscientização por parte de muitas igrejas batistas no Brasil e a Paraíba não está fora desta ação eclesiástica ambiental. É interessante notar que o grande impulsionador deste movimento que tem alcançado as igrejas de norte a sul do país foi a escolha de um tema ecológico para nortear as ações da igreja por parte da CBB em 2011. Entretanto, apesar do esforço da CBB e de algumas igrejas a ela convencionadas, que se uniram para transformar o discurso em prática e ações pontuais em ações contínuas, fazendo deste tema um marco para ações que viabilizem o exercício da ética e do cuidado com a integridade na criação de Deus, foi possível verificar que a representatividade das igrejas batistas brasileiras que divulgaram seu envolvimento com o tema do ano da CBB foi muito pouca.

Durante o mês de junho de 2011, a Associação Distrital das Igrejas Batistas do Litoral Paraibano (ADI$\mathrm{BAL}$ ) reuniu-se em sua $2^{\mathrm{a}}$ Assembleia Anual, na cidade de Cabedelo, PB. Neste encontro, por meio de suas lideranças locais, as Organizações de Pastores, Esposas de Pastores, Missionários, Seminaristas, Homens, Mulheres, Jovens, Adolescentes e Crianças reuniram-se em ambientes separados com o objetivo de discutir o tema do ano da CBB, Vida Plena e Meio Ambiente, e desafiar as igrejas batistas do litoral paraibano a serem padrão no cuidado do meio ambiente.

O que pôde ser observado durante as reuniões foi que houve uma interdição do tema por parte dos mediadores de todas as organizações, exceto na reunião da UFMBPB (Mulheres), que convidou um especialista para ministrar sobre o tema objeto da $2^{\mathrm{a}}$ Assembleia Anual da ADIBAL. Se assim não fosse, "o discurso manifesto não passaria, afinal de contas, da presença repressiva do que ele não diz; e esse não dito seria um vazio que mina, do interior, tudo o que se diz" (FOUCAULT, 1972, p. 36).

Esta interdição encontra explicação em Foucault quando este diz que a palavra proibida é um dos três grandes sistemas de exclusão que atingem o discurso. A contradição entre o dizer e o fazer pode ser explicada por Foucault quando este diz que esta é "a ilusão de uma unidade que se oculta ou que é ocultada" (FOUCAULT, 1972, p. 186). 
A comunidade batista em Cabedelo, PB é representada por doze igrejas e congregações ligadas à Convenção Batista Paraibana $(\mathrm{CBPb})$ e congrega em torno de cinco mil pessoas, o equivalente a dez por cento da população da cidade. Dentre estas, três foram escolhidas para dialogar com o tema do ano da CBB: Congregação Batista em Camboinha (CB Camboinha), Primeira Igreja Batista em Cabedelo (PIB Cabedelo) e Primeira Igreja Batista em Renascer (PIB Renascer), por serem aquelas que se deixaram conscientizar pelo discurso teológico ambiental quanto à sua responsabilidade de cuidar da criação de Deus e que produziram ações cooperativas, como organismo social, na diminuição dos riscos decorrentes da maior crise ambiental de todos os tempos, porque, segundo Schaeffer (1976, p. 84), “[...] os cristãos, que deveriam entender o princípio da criação, têm uma razão para respeitar a natureza, e, quando o fazem, isto resulta em benefício do homem".

A CB Camboinha movimentou a comunidade com ações sociais, a exemplo do Programa de Educação Pré-Escolar (PEPE), alcançando famílias carentes do bairro, moradoras da comunidade Vila Gameleira e Jardim Jericó, além de proporcionar palestras em encontros com mães da comunidade da Vila Gameleira e Jardim Jericó, estabelecendo parcerias por intermédio da Coordenadoria de Ação Social com a $\mathrm{CBPb}$.

Além disso, dois eventos importantes foram essenciais para o crescimento pessoal e social de todos: o Fórum pela Integridade da Criação, cujo objetivo foi "Desenvolver e encaminhar um projeto para a defesa da criação de Deus: o caso do lixo nas ruas de Camboinha"; e o Colóquio Comprometidos com a Ética, cujo objetivo foi "Promover e realizar uma manhã de diálogos sobre temas gerais da ética cristã, tanto no aspecto pessoal quanto social", com temas variados, entre os quais: Ética como princípio de toda a vida, Ética no casamento e na família, Ética no trabalho e na escola, Ética e justiça social, Ética ecológica, Ética econômica e Ética religiosa.

Na PIB Cabedelo, as sócias da MCA reuniram-se, conforme planejado, em 25 de janeiro de 2011, por volta das 19h30, em seu templo, para, juntas, glorificarem a Deus pela sua criação e pelas suas vidas. Com orações, leitura bíblica e cânticos, as mulheres foram preparadas para o estudo propriamente dito com a leitura do tema "Com Vida Plena, Preservemos o Mundo", enfatizando o cuidado com o meio ambiente como meta prioritária da $\mathrm{CBB}$, privilegiando, principalmente, a conscientização de reduzir o consumo de água, energia e alimentos para garantir a sustentabilidade do planeta.

A PIB Renascer tem investido na conscientização dos problemas ambientais de sua área de atuação por meio da ministração de palestras e da tentativa de implantar programas ecológicos. Dentre as atividades desenvolvidas pela Igreja no que diz respeito às questões ambientais, a MCA reuniu-se para compartilhar o estudo do mês de janeiro da revista Visão Missionária, atendendo ao tema da CBB para o ano de 2011, qual seja: Vida Plena e Meio Ambiente.

O que é de fundamental importância observar é se "o discurso em sua realidade material de coisa pronunciada ou escrita" (Foucault, 2009, p. 8), proferido nessa reunião, pôde ou não contribuir para a formação de uma nova consciência ecológica na comunidade do bairro do Renascer em Cabedelo, PB, porque entendemos que a Igreja é, potencialmente, uma instituição social com capacidade de formar uma cosmovisão e que, além disso, tem competência e facilidade para estabelecer uma autoridade moral e uma base ampla de membros.

Foi possível observar a compatibilidade entre os trabalhos das MCAs da PIB Cabedelo e da PIB Renascer. Ambas destinaram uma reunião especial para abordar a temática do ano da CBB apresentada na revista Visão Missionária. Aquilo que Foucault chamou de ritual pôde ser observado nos dois momentos, apesar de díspares. A ordem do culto foi preservada com orações, leituras bíblicas e louvores, a despeito de ser uma reunião de mulheres e não um culto formal. O estudo sobre o tema "Vida Plena e Meio Ambiente" só foi iniciado após o cumprimento de todo um ritual litúrgico, comum nas igrejas batistas. Esta experiência foi repetida e comparada nas duas igrejas em que o estudo foi observado.

Um ponto interessante a destacar é o fato de que, como as igrejas geralmente têm o perfil de seu líder, aqueles que são conscientes de seu papel cidadão e cristão, no que diz respeito ao cuidado com o meio ambiente, valorizaram as atividades propostas pelas revistas $\mathrm{Com}$ promisso, da JUERP, e Visão Missionária, da UFMBB.

$\mathrm{O}$ diálogo entre estes interlocutores e seus discursos foi considerado como o espaço interacional onde a linguagem pôde ser valorizada e onde se evidenciou a 
preocupação com a dimensão histórico-ideológica, que ofereceu elementos para uma reflexão sobre a transformação da sociedade e dos homens, já que o discurso encontra-se na exterioridade, no seio da vida social, sempre atravessado por vozes que o antecederam e que mantêm com ele constante duelo, ora o legitimando, ora o confrontando, para onde convergem as problematizações propondo a descoberta de outro sentido às palavras e às coisas (FOUCAULT, 1972, 2009; ALDRIGUE e ALVES, 2004).

A igreja e as organizações não governamentais cristãs podem, biblicamente, e devem, socialmente, definir sua atuação transitando da Teologia da Criação para a Missão Integral. Com base nesta perspectiva, Christoffersen (2010), sobre as responsabilidades crescentes das entidades religiosas no contexto atual da crise ambiental, sugere que as igrejas atuem mais intensamente, de forma integrada com a ciência, na intermediação política em prol da solução dos problemas ambientais, uma vez que a moral religiosa ajudaria a reverter os ganhos econômicos advindos da utilização sustentável da biodiversidade genética para as culturas locais e exercendo o seu papel como formadoras de opinião na conscientização das comunidades sobre os benefícios de uma vida equilibrada com a natureza e de uma exploração racional dos recursos naturais.

\section{Considerações}

Considerando que o objetivo geral deste artigo foi analisar o discurso teológico ambiental adotado por parte da Igreja Batista a partir da literatura bíblica e sua aplicação, especialmente, na comunidade evangélica batista da cidade de Cabedelo, PB, e que, para isso, foi preciso tratar certas especificidades, tais como a compreensão da visão multidimensional da Eco(Teo)logia, admitidas a partir dos conceitos etimológicos da Ecologia e da Teologia, da relação Sociedade e Natureza e da Missão Integral da Igreja; o conhecimento da abordagem de interface socioambiental na Tradição Discursiva Bíblica e promovendo a integração do discurso eco(teo)lógico em sua prática histórico-social, sob o olhar de Michel Foucault, pode-se observar que a Eco(Teo)logia é um campo de estudo capaz de integrar os discursos cientí- fico e religioso por ter foco na Ecologia e considerar a Espiritualidade como instrumento para a conscientização ambiental e não apenas uma Teologia em tons verdes, mas uma Teologia que incentiva a igreja em sua missão integral.

Verificou-se que a narrativa da criação, com ênfase no livro de Gênesis, é retomada em Apocalipse 4:11, apresentando o cântico da criação que diz: "Digno és, Senhor, de receber glória, e honra, e poder; porque tu criaste todas as coisas, e por tua vontade são e foram criadas.", donde se conclui que, para que seja formada uma nova consciência ecológica a partir da perspectiva de uma teologia ambiental, é preciso entender Deus como criador de todas as coisas e como o único a quem se deve dar glória, honra e poder.

Caminhando pelas trilhas literárias bíblicas, foi possível conhecer o texto do apóstolo Paulo em Romanos 8:22,23, que diz: "Porque sabemos que toda a criação geme e está juntamente com dores de parto até agora. E não só ela, mas nós mesmos, que temos as primícias do Espírito, também gememos em nós mesmos, esperando a adoção, a saber, a redenção do nosso corpo", que apresenta um plano para a redenção em que serão contemplados não somente a humanidade, mas a natureza. Neste escopo, o que se conclui é que para que haja uma mudança nos axiomas e uma transformação de paradigmas na comunidade evangélica é preciso entender que Deus estabeleceu um plano tanto para a criação quanto para a redenção do homem e da natureza.

Ao chegar à ultima trilha literária, no livro de Apocalipse 5:9-10, foi apresentado o cântico da redenção, que diz: "E cantavam um novo cântico, dizendo: Digno és de tomar o livro, e de abrir os seus selos; porque foste morto, e com o teu sangue compraste para Deus homens de toda a tribo, e língua, e povo, e nação; E para o nosso Deus os fizeste reis e sacerdotes; e eles reinarão sobre a terra".

Esta redenção, prevista desde o livro de Gênesis e que perpassa toda a tradição literária bíblica, tanto nos livros veterotestamentários quanto nos livros neotestamentários, encontra seu cumprimento nos versículos 1 e 2 do capítulo 21 do livro de Apocalipse, quando o apóstolo João escreve que viu: “... um novo céu, e uma nova terra. Porque já o primeiro céu e a primeira terra passaram, e o mar já não existe... vi a santa cidade, a 
nova Jerusalém, que de Deus descia do céu, adereçada como uma esposa ataviada para o seu marido".

Para a tradição literária bíblica, Jesus Cristo é o Redentor e por Ele e para Ele será restaurada toda a criação. E, como foi registrado pelo apóstolo Mateus em seu evangelho, no versículo 35 do capítulo 24 , "O céu e a terra passarão, mas as minhas palavras não hão de passar".

Ficou notabilizado o fato de que a Igreja Batista, objeto empírico de estudo desta pesquisa ${ }^{8}$, por meio da exposição de vários exemplos, está participando do processo de formação de uma consciência ambiental

\section{Referências}

ALDRIGUE, A. C.; ALVES, E. F. (Orgs.). Diálogos heterogêneos. João Pessoa: Editora Universitária UFPB, 2004.

ANDRADE, M. O. de. Diálogo de saberes: em busca de uma epistemologia ambiental. In: (Org.). Meio ambiente e desenvolvimento: bases para uma formação interdisciplinar. João Pessoa: Editora Universitária da UFPB, 2008.

BERKHOF, L. Teologia sistemática. Campinas: Luz para o Caminho, 1990.

BOFF, L. Espiritualidade. In: TRIGUEIRO, A. Meio ambiente no século 21. Rio de Janeiro: Sextante, 2003.

Espiritualidade, dimensão esquecida e necessária. Disponível em: < http://migre.me/eubRF>. Acesso em: abr. 2013.

CASTELLS, M. A sociedade em rede. 3. ed. São Paulo: Paz e Terra, 1999.

CÉSAR, J. L. Teologia e ecologia: queda de braço ou mãos dadas? 2012. Disponível em: <http://migre.me/8Ackf $>$. Acesso em: abr. 2013.

CHRISTOFFERSEN, M. L. Evolução, religião e ambiente (Evolution, religion and environment) - DOI: 10.5752/P.2175-5841.2010v8n17p109. Revista Horizonte de Estudos de Teologia e Ciências da Religião do Programa de Pós-Graduação fomentando a sensibilização de seus fiéis por meio de palestras ambientais, estudos bíblicos e projetos sociais na Paraíba e no Brasil.

O esperado é continuar possibilitando o diálogo eco(teo)lógico não só junto à comunidade batista de Cabedelo, PB, dando suporte para uma participação comunitária democrática e o desenvolvimento de novas atitudes de respeito para uma cooperação com a natureza a níveis locais, mas expandindo esta discussão por todo o Brasil, a fim de que esta possa promover uma mudança de paradigmas no que diz respeito à preservação e à conservação do nosso planeta.

em Ciências da Religião da Pontifícia Universidade Católica de Minas Gerais, v. 8, n. 17, abr./jun. 2010.

COSTA JÚNIOR, J. A teologia trinitária em Jürgen Moltmann. 2012. Disponível em: $<$ http://migre.me/8Acos $>$. Acesso em: abr. 2013.

CULLMANN, O. A formação do novo testamento. São Leopoldo: Sinodal, 1996.

DE CHILE.NET. Diccionario Etimológico. Disponível em: <etimologias.dechile.net/>. Acesso em: abr. 2013.

FOUCAULT, M. A arqueologia do saber. Tradução de L. F. B. Neves; revisão de L. Vassalo. Petrópolis: Vozes; Lisboa: Centro do Livro Brasileiro, 1972. rense, 1987.

A arqueologia do saber. 3. ed. Rio de Janeiro: Fo. A ordem do discurso. Tradução de L. F. A. Sampaio. 19. ed. São Paulo: Loyola, 2009.

HERCULANO, S. C. Elementos para um debate sobre a interdisciplinaridade. In: (Org.). Meio ambiente: questões conceituais. Niterói, Monografia (Pós-Graduação em Ciências Ambientais) - UFF RioCor, 2000.

HOUSE, R. P. Teologia do Antigo Testamento. São Paulo: Vida, 2005.

\footnotetext{
${ }^{8}$ LIMEIRA, Amelia Ferreira Martins. Eco(Teo)logia: o discurso teológico ambiental e sua prática na comunidade evangélica batista da cidade de Cabedelo, PB 173p. João Pessoa, Dissertação (Mestrado) - Programa Regional de Pós-Graduação em Desenvolvimento e Meio Ambiente, Pró-Reitoria de Pós Graduação, Universidade Federal da Paraíba, 2011.
} 
KIDNER, D. Gênesis: introdução e comentário. São Paulo: Vida Nova, 2004.

LIMA, G. F. C. A diferenciação do campo da EA no Brasil: concepções, identidades e disputas. In: TORRES, M. B. R.; RIBEIRO, M. F. R.; LEANDRO, A. L. A. L.; CAMACHO, R. G. V. (Orgs.). Teorias e práticas em Educação Ambiental. Mossoró: UERN, 2009.

LIMEIRA, A. F. M. Eco(Teo)logia: o discurso teológico ambiental e sua prática na comunidade evangélica batista da cidade de Cabedelo, PB. João Pessoa, Dissertação (Mestrado em Desenvolvimento e Meio Ambiente) - UFPB, 2011.

; ANDRADE, M. O. de. Diálogo entre a tradição bíblica e a construção do discurso teológico ambiental cristão. Revista Horizonte de Estudos de Teologia e Ciências da Religião do Programa de Pós-Graduação em Ciências da Religião da Pontifícia Universidade Católica de Minas Gerais, Belo Horizonte, v. 10, n. 26, p. 603-618, abr./jun. 2012 - ISSN: 2175-5841.

LOPES, A. N. G. Ecologia: uma perspectiva cristã-reformada. 2010. Disponível em: <http://migre.me/8Ad52>. Acesso em: abr. 2013.

MARSHALL, H. I. Teologia do Novo Testamento: diversos testemunhos, um só evangelho. São Paulo: Vida Nova, 2007.

MURAD, A. O Núcleo da Ecoteologia e a Unidade da Experiência Salvífica. Rev. Pistis Prax., Teol. Pastor., Curitiba, v. 1, n. 2, p. 277-297, jul./dez. 2009.
PELIZZOLI, M. L. Correntes da Ética Ambiental. Petrópolis: Vozes, 2003.

PUC-RIO - Certificação Digital $n^{\circ}$ 0420965/CA. Celebração da vida: diálogo com a Teologia Ecológica de Jurgen Moltmann. Disponível em: <http://migre.me/eubMw>. Acesso em: maio 2013.

PFEIFFER, C. F. Comentário Bíblico Moody. São Paulo: Editora Batista Regular, 1999.

REIMER, H. Paz na criação de Deus - esperança e compromisso. Estudos Teológicos, São Leopoldo, v. 51 n. 1, p. 138-156, jan./jun. 2011.

REIMER, I. R. Criação e Bíblia. In: BEOZZO, J. O. Curso de verão ano $X X$ : Ecologia: Cuidar da Vida e da Integridade da Criação. São Paulo: CESEP: Paulus, 2006.

SCHAEFFER, F. Poluição e a morte do homem: uma perspectiva cristã da ecologia. Rio de Janeiro: Juerp, 1976.

STOTT, J. A missão cristã no mundo moderno. Viçosa: Ultimato, 2010. O discípulo radical. Viçosa: Ultimato, 2011.

VIRKLER, H. A. Hermenêutica avançada: princípios e processos de interpretação bíblica. São Paulo: Vida, 2001.

WOLFF, H. W. Antropologia do Antigo Testamento. São Paulo: Hagnos, 2007.

Recebido em 06 de fevereiro de 2013. Aceito em 23 de maio de 2013. Publicado em dezembro de 2013. 